\title{
Paradox of life among survivors of bladder cancer and treatments*
}

\author{
Paradoxo da vida entre sobreviventes do câncer de bexiga e tratamentos \\ Paradoja de la vida entre supervivientes del cáncer de vejiga y tratamientos
}

\author{
Miriam Lopes ${ }^{1}$, Lucila Castanheira Nascimento ${ }^{2}$, Márcia Maria Fontão Zago ${ }^{1}$
}

How to cite this article:

Lopes M, Nascimento LC, Zago MMF. Paradox of life among survivors of bladder cancer and treatments. Rev Esc Enferm USP. 2016;50(2):222-229. DOI: http:// dx.doi.org/10.1590/S0080-623420160000200007

\begin{abstract}
* Extracted from the thesis "Os significados da depressão entre pacientes com câncer de bexiga em seguimento terapêutico", Escola de Enfermagem de Ribeirão Preto, Universidade de São Paulo, 2014.

${ }^{1}$ Universidade de São Paulo, Escola de Enfermagem de Ribeirão Preto, Departamento de Enfermagem Geral e Especializada, Ribeirão Preto, SP, Brazil.

${ }^{2}$ Universidade de São Paulo, Escola de Enfermagem de Ribeirão Preto, Departamento de Enfermagem Materno-Infantil e Saúde Pública, Ribeirão Preto, SP, Brazil.
\end{abstract}

\begin{abstract}
Objective: To interpret the meanings attributed to the experience of bladder cancer among survivors in therapeutic follow-up. Method: Qualitative methodological approach, based on medical anthropology and narrative methodology. After approval by the research ethics committee of a public university hospital, data were collected from January 2014 to February 2015, by means of recorded semi-structured interviews, direct observation and field journal entries on daily immersion with a group of six men and six women, aged between 57 and 82 years, in therapeutic follow-up. Narratives were analyzed by means of inductive thematic analysis. Results: The meanings revealed difficulties with the processes of disease and treatment, such as breakdown of normal life, uncertainty about the future due to possible recurrence of the disease, difficulty with continuity of care and emotional control, relating it to conflicting ways of understanding the present life. Thus, the meaning of this narrative synthesis is paradox. Conclusion: Interpretation of the meaning of experience with bladder cancer among patients provides nurses with a comprehensive view of care, which encompasses biological, psychological and social dimensions, and thereby systematizes humanized care.
\end{abstract}

\section{DESCRIPTORS}

Urinary Bladder Neoplasms; Survival; Culture; Anthropology, Medical; Oncology Nursing. 


\section{INTRODUCTION}

According to a 2012 survey by the World Health Organization (WHO) on global cancer estimates, there were 429,800 new cases of bladder cancer and 165,100 deaths from this disease worldwide ${ }^{(1)}$. In Brazil in 2014, there were about 6,750 new cases in men and 2,190 in women ${ }^{(2)}$.

Smoking is the main risk factor for bladder cancer, which is the most common type of urinary tract cancer, and affects more men than women ${ }^{(1,3)}$. There are other factors linked to development of this cancer, such as chronic infection by the parasite Schistosoma haematobium, and occupational exposure to carcinogens such as amines and aromatic hydrocarbons, commonly used by industries in the processing of paints, dyes, metal and petroleum products ${ }^{(1)}$.

Bladder cancer, also known as urothelial carcinoma, appears as a heterogeneous group of tumors with distinct behaviors, treatments and prognoses ${ }^{(4)}$. The main sign of the disease is the presence of variable amounts and frequencies of hematuria in urine, and it is diagnosed by means of urinalysis, cystoscopy, and biopsy of the tumor by transurethral resection (TUR) of the bladder. The latter is also used for staging of the disease, which will guide the medical professional to provide the best treatment ${ }^{(3)}$.

According to clinical studies, in $80 \%$ of patients bladder cancer is diagnosed at a non-invasive stage, when conservative treatments are more effective, and the prognosis is better ${ }^{(5)}$. However, prognosis depends on several factors such as stage of the disease, histological tumor grade, multifocality (more than three lesions), presence of lymphatic invasion, association with in situ carcinoma, morphology and pattern of gene mutation ${ }^{(4)}$.

According to stage of the bladder cancer, therapeutic procedures commonly used include TUR, intravesical therapy with Bacillus Calmette-Guérin (BCG), adjuvant and neoadjuvant chemotherapy and partial or radical cystectomy ${ }^{(3)}$. One study found that even in cases of a type of cancer where therapy differs from the others, patients undergoing treatment for bladder cancer have some reactions and attitudes similar to other cancer patients, but the experiences regarding surgical treatments are individual ${ }^{(6)}$.

After diagnosis with cancer, the period of survival begins for patients and their families. According to the National Cancer Institute ${ }^{(7)}$, cancer survivors are those who achieve balance in a new life and well-being, with new adjustments to physical and emotional changes with social support and medical follow-up, despite the fear of recurrence of the disease.

Transurethral resection surgery, the main therapy for removal of vesical tumors, is considered to be less harmful, and intravesical immunotherapy with BCG causes fewer reactions than anticancer chemotherapy and radiotherapy. Although bladder cancer appears to be "less aggressive", its psychological and physical effects interfere in its victims' lives, and therefore requires a comprehensive view by the health professionals who care for these patients.

In both national and international literature, there are few studies with a qualitative approach focused on the experiences of bladder cancer patients. The aim of this study was to interpret the meanings attributed to the experience of bladder cancer by survivors in therapeutic follow-up. The main question of the study was: How do bladder cancer patients narrate their experience with the disease and its treatments?

\section{METHOD}

The survey was conducted based on the theoretical and methodological framework of medical anthropology and narrative methodology. Medical anthropology integrates health, disease and culture, in order to investigate beliefs and practices, and relate these to psycho-biological and socio-cultural changes in the health-disease process ${ }^{(8)}$. Culture is a symbolic and public system focused on the individual, who uses it to interpret their world and their actions. Therefore, culture is learned, shared and standardized, and its constituent elements are values, symbols, rules and practices $^{(9)}$. In order to understand the disease process, the explanatory model (EM) structures research of the models adopted by different social groups when they experience disease. Therefore, EMs are cultural models in which people organize the experiences of the disease, giving them meaning both for themselves and for members of their context, framing them as a cultural experience ${ }^{(10)}$.

In narrative methodology, individual narratives of disease are access routes to shared meanings of illness ${ }^{(11)}$. The methodology proposed by Squire ${ }^{(12)}$ for individual narrative method focused on the cancer experience that the present study adopts, produces sequential, significant stories that represent the experiences, and their reconstitution and expression, thereby revealing the transformations or changes in social identity and life with the disease. The project was approved by the Human Research Ethics Committee of the study setting under CAEE protocol no. 07484212.0.0000.5393. All participants in the study signed a free and informed consent form. To ensure anonymity, participants' names are fictitious, and were selected by the patients themselves.

Participants were approached via telephone, and at the outpatient care unit for oncological urology at a public university hospital in the interior of São Paulo state. The following selection criteria were used: patients diagnosed with bladder cancer; post surgical treatment, TUR and/or cystectomy; at least 3 months of postoperative follow-up care; no restrictions on sex; older than 18 years; no restriction on level of education and socio-economic status; having physical and psychological conditions to participate; and living in the city of Ribeirão Preto, São Paulo, or the municipalities that compose the DRS XIII, located within a radius of 100 kilometers $(\mathrm{km})$ of the city. Data were collected in an outpatient care service and in the participants' homes, from January 2014 to February 2015.

Data collection techniques were direct observation and recorded semi-structured interviews, guided by the following questions: When and how did you discover you had cancer? What went through your mind when you received the news? What are the treatments you have undergone for the disease? How is your life today with cancer and treatments? 
Finally, did the disease interfere in any activity that you did before and can no longer do, or no longer have the desire to do? Other questions were formulated according to the content of the participants' narratives. Furthermore, some information was supplemented in order to obtain sociocultural and therapeutic data. On average, two interviews were carried out with each participant, and some required more to increase the depth of data.

After each interview was transcribed, and observations and reports from the field journal were systematized, individual narratives of each participant were developed, complemented by each additional interview, and then subjected to thematic inductive analysis ${ }^{(13)}$. After reading each narrative and the set of narratives together, the data were classified into categories with which the authors developed units of meaning, e.g., descriptions of the processes experienced by the participants, with their knowledge of and actions related to the disease and treatments, explained by motivations and justifications. These units of meaning compose the explanatory models for each participant.

In the next stage, themes that represented beliefs, values and symbolism embedded in the ideas and practices employed in the experiences were sought in the narrative discourses. From this stage, the narrative synthesis related to the experience with bladder cancer and treatments was constructed. In this narrative synthesis, the meanings were organized sequentially, along with the explanatory models narrated by all participants, discussing them with the theoretical concepts and literature on the theme. To interpret the meaning expressed by a theme, the parts and the whole of each individual narrative and narrative synthesis were analyzed, dialoguing with the meanings, theoretical framework and literature, to build coherent explanations. Thus, the authors developed the hermeneutical circle and obtained the fusion of horizons between participants and researchers ${ }^{(12)}$.

To achieve methodological rigor of the study, the authors described the development of research in detail, selected participants who experienced the phenomenon of having cancer in follow-up care, conducted multiple data collection sessions with most participants, maintained longterm contact with them, used their accounts in the narratives, and described their life and clinical contexts. Each step of the analysis was developed in continuous discussion between the main investigator and advisor of the study, and the results are supported by current theory and literature ${ }^{(14)}$.

Participants were six men and six women (Rubão, Manuel, Paulo, Antônio, Pedro, José, Lourdes, Rosa, Letícia, Ira, Ana, Marília), a homogeneous sample in regard to sex, aged between 57 and 82 years, the majority (8) were married, had a level of education that varied from incomplete primary education (5) to incomplete higher education (1) and retired (10), Catholic (8), and residents in the town and region of the study. Staging of urothelial carcinoma was variable from the early to advanced stage. The time of diagnosis of the disease ranged from 1 to 10 years. For treatment, all participants underwent TUR, in association with BCG for most, and there were three cases of cystectomy. Only one participant required application of temporary antineoplastic chemotherapy drugs, the amount of TUR was one to three surgeries, while undergoing cystoscopy was one to 11 . The comorbidities present were hypertension, diabetes mellitus, dyslipidemia, prostatism, hyperthyroidism, stroke, angina, obesity, previous stroke, acute myocardial infarction and asthma.

The terms presented in italics are statements made by participants, and illustrate the analysis of the authors.

\section{RESULTS}

\section{Meanings of bladder CANCER AND ITS treatment}

In the exploratory lay model of the participants, bodily changes or signs and symptoms of bleeding, clots in the urine and painful urination mean that the body is not working properly, a condition that may be temporary or not, such as a possible infection, loose vein or dropped stone, and requires a solution. Initially, participants' understanding minimized the severity of the condition in which they were delaying the search for care, letting several bleedings occur until bleeding with clots was accentuated.

According to the participants' narratives, delay in diagnosis was related to social, cultural and economic factors, of both the patients and their relatives, in regard to the official health system. Late diagnosis meant less chance of cure, requiring ongoing medical evaluation for several years, more aggressive treatment such as removal of the bladder (cystectomy), frequent BCG applications, and undergoing urostomy in the cases of Rubão, Lourdes and Rosa.

According to Ana, Paulo and Pedro, in some situations, medical communication occurred so as to soften the diagnosis, using the terms tumor, malignant little tumor, or avoiding the name of the disease. For other participants, it was incisively being straightforward. The manner in which the participants came to know of their diagnosis was a moment of surprise or confirmation of what was expected, since cancer was part of their social life.

They handled the situation with despair, apprehension, sadness and shock, learned emotions in social life after assessment of the severity of the disease - cancer, malignant disease. In the culture of the survivors, one way of symbolizing the situation was through metaphors: it is a time when anyone would fall! You lose your footing, you say, 'and now, where do I run to?' It seems like the world came crashing down!

Cancer is viewed as a serious, incurable disease, as highlighted by Antônio and Paulo: it is a dangerous disease that everyone is afraid of getting; it is something from the devil. There was also rejection to pronounce the name of the disease, as expressed by Paulo and Leticia, they don't even say the name; they could only say who. Considering the severity of the disease, most of the men and women participants felt responsible to protect their family from the chaos and suffering surrounding them, demonstrating strength to fight and face the illness: we have to be strong and we have to face it; have faith in overcoming this.

For Rubão, the cause was regarded as punishment for some inappropriate behavior in the past or for doing wrong 
things, or in the cases of Antônio, José and Letícia, from working with carcinogenic substances such as paint, and smoking. According to Paulo and Marilia, the cause had a magical-religious explanation grounded in destiny, while Manuel referred to a birth defect or natural cause being his strangulated prostate. However, the hereditary (genetic) cause of the disease, present in family members, was also associated with the cause: you're born with a seed that can trigger cancer.

The way in which the narratives of treatment was developed highlighted the patients' acceptance of proposed medical treatments. The participants implicitly understood that this was the best option, although they caused discomforts and changes in life plans. All of the therapies generate temporary or permanent difficulties, as expressed by Manuel: saying that surgery does not hurt, does not bleed, it's bullshit! But it's a necessary evil. If you do not bleed, the body does not defend itself.

Rubão, Lourdes and Rosa had more severe stages of the disease, and underwent radical cystectomy with urostomy. This is the procedure that attacks the patient, changes everyday life, and imposes daily care of the stoma and its collection bag, which raises concerns with odor and excretion of urine, requiring changes in dress style, not always accepted, in addition to dependence on others and damages to self-image. Over time, the presence of the urostomy is regarded as normal.

The other participants underwent treatment with TUR and BCG application. TUR is a surgical procedure that requires hospitalization and pre - and postoperative procedures: Hospitalized one or two days before the scraping. The surgery requires a few days of recovery, and complications can occur, such as bleeding, presented by Manuel. The presence of the urethral catheter was the main difficulty due to the length of stay and the annoyances it caused: I stayed with the probe until it got lighter because blood and a lot of filth was coming out, because of the disease. BCG application also had difficult reactions that are hard to bear, independent of the participants' sex: she's strong as hell. After you go to the bathroom for first time, it bothers you, and burns; it deregulates your urine.

In all the narratives, the storyline of the experience with these therapies focused on physical suffering, it is a horrible, terrible suffering, and disruption of daily life, such as the inability to perform manual, professional or domestic activities, as reported by Antônio, Paulo, Pedro, Rosa and Lourdes. Although they presented complications in life, the therapies reported are those that enabled the patients to survive. The number of TUR procedures was performed because of recurrence of the disease, and the participants were aware of this aspect. Therefore, periodic medical follow-up is necessary to control the disease, and as Antonio pointed out: it has not come back so far, but it could. Thus, continuity of life without the disease is always an uncertainty: there's always that question of whether it will come back! You have to have follow-up care; that is normal. This makes us tired, but it doesn't shatter us!

Compensatory logic to handle and bear the reactions to therapies for bladder cancer is the assessment that the participants make in relation to reactions from systemic antineoplastic chemotherapy: when I learned I did not need it, I was relieved, because your hair falls out. If you go out on the street, people know right away that you have cancer... It is better to do $B C G$.

In addition to the proposed medical treatment, the authors of this study noted that the participants considered using medicinal plants for their curative or palliative properties: I use tea of horseweed - a medicinal root. I take a couple of clips from the root, and put it in a liter of cachaça. Every day, before lunch, I take a little. Every plant that has thorns is strong and good! I use aloe vera, a natural anti-inflammatory... one has to have a buzzard's stomach! It's bad like the plague.

As a therapeutic intervention, religion was another source of support: we had a friend who said it would be good to do some prayers! I have to fear God and not the disease, because He is greater.

With ongoing treatments, even suffering, participants felt a moral obligation to participate in their treatment, which maintained their confidence to achieve the desired result: I do my part, I do everything the doctors ask.

During the trajectory of the illness, the patients reconsidered their experiences, seeking logical and compensatory practices in order to regain the sense of normalcy they had prior to the disease, as they indicated when narrating about their present life: I continue with the normal life I had. I feel good...I'm good... life is delicious, knowing to live it.

Sexual activity was little reported by the participants. Only three participants deplored the loss of their sex life. Rosa (urostomy) described with laughter how her husband no longer initiated sex, due to her ill health or age of 70 years. José reported he had problems with erection and impotence.

As for future plans, although they were elderly, had cancer and other chronic associated diseases (hypertension and diabetes mellitus, among others), survival and meanings of the future were redeveloped. Rubão reported he did not make plans for the future, and that he was getting by, while Paulo wanted to acquire material goods, travel, and Rosa just wanted to see my grandchildren get married.

\section{DISCUSSION}

The disease process ${ }^{(9)}$ is characterized by recognition of the signs and symptoms indicative that the body is not healthy. The definition of the diagnosis and choice of treatment are negotiated, in general, by the patient and their family, and friends such as the pharmacist friend; as well as evaluation of outcomes of treatments undergone that, when evaluated as not effective or severe, lead them to seek other treatments. In the common sense of Western society, pain and bleeding are indications that there is something seriously wrong with the body, preventing daily activities and being a cause for concern ${ }^{(8)}$.

Communication about the diagnosis by medical professionals is often inappropriate, either because it is softened or considered serious, because they perpetuate the symbols of the stigmatized disease as being very serious ${ }^{(15)}$.

When describing the disease as malignant, the participants recognized it as generating suffering and undermining 
future life. The use of metaphors, which are figures of speech, helped the participants to comprehend and give meaning to a complex life process. This form of self-expression is common among cancer patients in Western society and Brazilians ${ }^{(16)}$. The social stigma of the disease, driven by health care and media professionals ${ }^{(15)}$, provokes a sense of rejection when pronouncing its name. Thus, the disease becomes real, and its meaning is based on a personal, cultural and social construction.

With the diagnosis of cancer, the participants recognized the change in their identity from being healthy to being a cancer survivor, with the disease embodied to the individual ${ }^{(17)}$. Attitudes for coping with the disease, such as strength to fight and face the illness, are required to meet the expectation of the social norm to face difficult situations ${ }^{(18)}$.

One of the key aspects to grasp the meaning of the patients' experiences was their explanations and beliefs about its cause $\mathrm{e}^{(9)}$. In the medical model, smoking is the cause of bladder cancer ${ }^{(3)}$. Explanations for etiology of the cancer involved psychological, social (family and social relationships), spiritual and biological aspects. The authors observed that the patients attributed the cause of their illness to moral behaviors and individual characteristics. These explanations for cancer enable understanding that the explanatory models used are not pure, and are influenced by the language of the medical model, considering that all the study participants were in ongoing therapy, with frequent contact with health professionals and other patients. This influence is important because the participants needed to construct images from their socio-cultural environment and the medical environment, so that they could understand the "why" of the disease or its meanings, for which they required an explanation that transcended the individual body and medical diagnosis ${ }^{(9,15)}$.

Confidence in medical treatment is defined by the doctor-patient relationship, based on social recognition of medical knowledge and technological resources used in therapy, which can promote successful outcomes ${ }^{(8)}$.

Regarding surgical treatment by cystectomy and consequent presence of ostomy, one study ${ }^{(19)}$ pointed out that the facilitators related to the person, for self-care, are to assign positive meaning to the stoma; receive guidance on care of the stoma and lifestyle changes, and on preparation for this experience while still in the preoperative phase; present psychological stability; and seek comfort in faith and religion. Yet the conditions related to the community are to receive equipment from the government free of charge; support from family and the multidisciplinary health care team, especially nurses; and contact with other people with stoma.

Medicine treats the patient's body, but the evils of the soul require other therapeutic interventions ${ }^{(8)}$. Among groups of Brazilians, it is culturally recognized that the cure of a disease also requires actions for health in the folkloric realm. A popular practice of care learned in the family and social context for the patient is the use of medicinal plants, teas and therapeutic fluids.

All the of participants expressed that religion, another type of therapeutic intervention, helped the patients, in extreme situations, to understand the inexplicable and accept the present situation, seeking spiritual meaning that encouraged them to deal with the adversities of bladder cancer and its treatment. Religious concepts are learned in the family and social environments into which the patient is inserted, and are used in all stages of experience with the disease. In a narrative study of cancer patients ${ }^{(20)}$, the authors reported that religious practice is a crucial form of support for success in the conventional treatment of bladder cancer and to beat the disease.

Upon reconsidering their experiences, the patients underscored the common sense logic that they needed to go through unexpected situations to recover the sense of normalcy they had before the disease (or at least as normal as possible for their new life with illness), for common thinking for different groups of cancer patients ${ }^{(9)}$.

Some of the participants said that because they were elderly, sex was not important. Sex is part of the sexuality of people, it changes with age, but the ability to express affection remains important ${ }^{(21)}$. Considering the socio-cultural context of the participants, the authors of the study observed that issues around sex and sexuality were suppressed.

The experience of the disease and treatment exposed the patients to the need to overcome personal and social vulnerability, which involves gradations and changes throughout the process. The patients were not permanently vulnerable, they were temporarily vulnerable because of their experience with bladder cancer in a certain time and space ${ }^{(22)}$.

The patients' ways of thinking and acting in the face of being sick with bladder cancer and treatments were the result of secular rationality, influenced by the medical model that gave them directions, and supported their actions to deal with the experience. The rationale employed by the participants reveals the relationships of the body with the mind, and the individual's, social, cultural, natural and spiritual worlds. The logic is to fight the consequences of the disease and therapeutic effects, to seek internal and external strategies to prevent the continuation of suffering ${ }^{(23)}$. The uncertainty of recurrence of the disease and the finitude of life are thoughts designed so as not to interfere with its continuity. This is a negotiation with destiny, spirituality and family.

The meanings presented in the narrative synthesis on the experience of the disease and its treatments in the present study are similar to one national study with adult and elderly cancer patients, that was grounded in interpretative medical anthropology ${ }^{(15)}$, and which demonstrated that thoughts and practices are culturally standardized, and incorporate feelings valued by groups of patients, regardless of the type of cancer and treatment used. Suffering from cancer and uncertainty about the future are units of meaning identified in one international interpretative study with different groups of elderly cancer patients ${ }^{(24)}$. In these studies, family support and religious activity were the patients' main strategies for coping because they provided security and hope for survival.

Comparing the results of this study with an international qualitative study with bladder cancer patients ${ }^{(25)}$, it is 
worth noting that the themes of experience with the disease were similar in both studies, as the interference of treatment on maintaining employment of the patients, who felt forced to retire and expressed a feeling of being punished by having the disease, and by frequent applications of BCG applications due to tumor recurrence, which caused depression.

The meanings described in this study expand and deepen the characteristics of the experiences of patients with bladder cancer and its treatments reported in the literature.

The stories narrated by participants about difficulties with the process of disease and treatments, and the relationship with conflicting thoughts about their present life lead the authors to interpret this narrative synthesis, in essence, as the meaning of paradox ${ }^{(26-27)}$.

The narratives described intense feelings with the diagnosis, including anguish, sadness, finitude, and the logic of compensation was emotional control, because it is a necessary evil. Before their suffering, ruptures of life, uncertain future due to the possibility of recurrence of the disease, and the need for continuing treatment to control the disease, the patients felt morally compelled to reframe their life with the help of religious support and family: we grow, we change. There is a way of thinking and acting to move forward, to survive with a new normal life, with optimism, I feel good; I am happy, everything went right. Only then surviving the disease is possible, as a paradox. This is a valued practice, learned in the sociocultural contexts of the patients with unexpected chronic diseases. These attitudes were also observed in one qualitative systematic review study ${ }^{(28)}$ on the experience with elderly cancer patients. The authors showed that among elderly cancer patients, resources and strategies are replaced to cope with feelings of uncertainty, fear and anxiety. The participants of the present study searched to cultivate attitudes to "fight" negative feelings, in spirituality and hope, to avoid talking about the disease, and to portray themselves to others as being happy and unafraid of the future.

The paradox of life with cancer did not mean that the participants' experiences were resolved. The experience of the paradox is cyclical, depends on evolution of the disease, and occurs with different intensities, and on the ability of the participants to react and resist, because cancer is an experience that leads to complex psychological, existential, spiritual, physical, cultural and socioeconomic interactions, with dynamic, fluid and ambiguous situations ${ }^{(27)}$.

\section{CONCLUSION}

One of the limitations of the present study was the refusal of some participants to be interviewed again, so that the authors could deepen and further explore the narratives.

The identification of explanatory models in the individual narratives centered on the cancer experience proved to be an essential strategy to identify and describe the subjective dimensions of the participants' experiences with bladder cancer. The findings of this study clearly show that having bladder cancer is to have "the disease," regardless of tumor type. The meanings reveal similarities with other studies conducted on the subject, with other social groups.

Despite all the suffering arising from transformations from the experience, all of the participants had a moral obligation to fight, to win, to rebalance their life with family and religious support. The paradox of meaning is this way of thinking and acting for forward movement, and aims to survive the disease upon resumption of normal life.

Knowledge of the feelings and meanings attributed to the experience of bladder cancer among the participants in ongoing treatment enables nurses to have a comprehensive view of care, that includes biological, psychological and social dimensions of patients, and thereby systematized humanized care.

\section{RESUMO}

Objetivo: Interpretar o significado atribuído à experiência do câncer de bexiga entre sobreviventes em seguimento terapêutico. Método: Empregou-se a abordagem metodológica qualitativa, embasado pela antropologia médica e método narrativo. Após aprovação do Comitê de Ética, os dados foram coletados de janeiro 2014 a fevereiro de 2015, por meio de entrevistas semiestruturadas gravadas, observação direta e registros no diário de imersão com grupo de seis homens e seis mulheres, entre 57 e 82 anos, em seguimento terapêutico em um hospital público universitário. As narrativas foram analisadas por meio da análise temática indutiva. Resultados: Os sentidos revelam as dificuldades com o processo da doença e do tratamento, como rupturas na vida, futuro incerto pela possibilidade de recidiva da doença, continuidade do tratamento e controle emocional, relacionando-se com as ponderações contraditórias da vida atual. Assim, o significado desta síntese narrativa é de paradoxo. Conclusão: A interpretação do significado da experiência com câncer de bexiga entre os adoecidos permite ao enfermeiro um olhar integralizado do cuidado que perpasse as dimensões biopsicossociais dos adoecidos e, com isso, sistematize a assistência de maneira humanizada.

\section{DESCRITORES}

Neoplasias da Bexiga Urinária; Sobrevivência; Cultura; Antropologia Médica; Enfermagem Oncológica.

\section{RESUMEN}

Objetivo: Interpretar el significado atribuido a la experiencia del cáncer de vejiga entre supervivientes en seguimiento terapéutico. Método: Se empleó el abordaje metodológico cualitativo, fundado en la antropología médica y el método narrativo. Después de la aprobación del Comité de Ética, los datos fueron recogidos de enero de 2014 a febrero de 2015, por medio de entrevistas semiestructuradas grabadas, observación directa y registros en el diario de inmersión con grupo de seis hombres y seis mujeres, entre 57 y 82 años, en seguimiento terapéutico en un hospital público universitario. Las narrativas fueron analizadas mediante el análisis temático inductivo. Resultados: Los sentidos desvelan las dificultades con el progreso de la enfermedad y del tratamiento, como rupturas en la vida futura incierta por la posibilidad de recidiva de la enfermedad, continuidad del tratamiento y control emocional, relacionándose con las ponderaciones contradictorias de la vida actual. Así, el significado de esta síntesis narrativa es de paradoja. Conclusión: La interpretación 
del significado de la experiencia con cáncer de vejiga entre los enfermos le permite al enfermero una mirada integrada del cuidado que supere las dimensiones biopsicosociales de los enfermos y, con eso, sistematice la asistencia de manera humanizada.

\section{DESCRIPTORES}

Neoplasias de la Vejiga Urinaria; Supervivencia; Cultura; Antropología Médica; Enfermería Oncológica.

\section{REFERENCES}

1. Torre LA, Bray F, Siegel RL, Ferlay J, Lortet-Tieulent J, Jemal A. Global Cancer Statistics, 2012. CA Cancer J Clin [Internet]. 2015 [cited 2015 May 04];65(2):87-108. Available from: http://onlinelibrary.wiley.com/doi/10.3322/caac.21262/pdf

2. Brasil. Ministério da Saúde; Instituto Nacional do Câncer José Alencar Gomes da Silva, Coordenação de Prevenção e Vigilância. Estimativa 2014: Incidência de câncer no Brasil. Rio de Janeiro: INCA; 2013.

3. Hall MC, Chang SS, Dalbagni G, Pruthi RS, Seigne JD, Skinner EC, et al.; American Urological Association. Guideline for the management of nonmuscle invasive bladder cancer (stages Ta, T1, and Tis): 2007 update. J Urol. 2007;178(6):2314-30.

4. Sociedade Brasileira de Oncologia Clínica. Manual de condutas. Gramado (RS): SBOC; 2011. Câncer de bexiga; p. 173-90.

5. Hardt J, Gillitzer R, Schneider S, Fischbeck S, Thüroff JW. Coping styles as predictors of survival time in bladder cancer. Health [Internet]. 2010 [cited 2015 May 25];2(5):429-34. Available from: http://file.scirp.org/Html/1776.html

6. Fitch MI, Miller D, Sharir S, McAndrew A. Radical cystectomy for bladder cancer: a qualitative study of patients experiences and implications for practice. Can Oncol Nurs J [Internet]. 2010 [cited 2015 May 06];20(4):177-81. Available from: http://canadianoncologynursingjournal. com/index.php/conj/article/view/172/180

7. National Cancer Institute. Survivorship [Internet]. Bethesda (MD); 2014 [cited 2015 Jun 18]. Available from: http://www.cancer.gov/aboutcancer/coping/survivorship

8. Helman C. Cultura, saúde e doença. $5^{\text {a }}$ ed. Porto Alegre: Artmed; 2009.

9. Buetto LS, Zago MMF. Meanings of quality of life held by patients with colorectal cancer in the context of chemotherapy. Rev Latino Am Enfermagem [Internet]. 2015 [cited 2016 Jan 04];23(3):427-34. Available from: http://www.scielo.br/pdf/rlae/v23n3/0104-1169rlae-0455-2572.pdf

10. Kleinman A. Patients and healers in the context of the culture: an exploration of the borderland between anthropology, medicine and psychiatry. Berkeley: University of California Press; 1980.

11. Mattingly C. Healing dramas and clinical plots: the narrative structure of experience. 7nd ed. Cambridge: Cambridge University Press; 2007.

12. Squire C. From experience-centred to socioculturally-oriented approaches to narrative. In: Andrews M, Squire C, Tamboukou M, editors. Doing narrative research. 2nd ed. London: Sage; 2012. p. 47-71.

13. Braun V, Clarke V. Using thematic analysis in psychology. Qual Res Psychol. 2006;3(2):77-101.

14. Noble H, Smith J. Issues of validity and reliability in qualitative research. Evid Based Nurs. 2015;8(2):34-5.

15. Tavares JSC, Trad LAB. Metáforas e significados do câncer de mama na perspective de cinco famílias afetadas. Cad Saúde Pública [Internet]. 2005 [citado 2007 jul. 15];21(2):426-35. Disponível em: http://www.scielosp.org/pdf/csp/v21n2/09.pdf

16. Carpenter J. Metaphors in qualitative research: shedding light or casting shadows? Res Nurs Health. 2008;31(3):274-82.

17. Víctora C. Social suffering and the embodiment of the world: contributions from anthropology. Rev Eletrôn Comun Inform Inov Saúde [Internet]. 2011 [citado 2014 jul. 12];5(4):1-17. Disponível em: http://www.reciis.icict.fiocruz.br/index.php/reciis/article/viewFile/552/944

18. Karnilowicz W. Identity and psychological ownership in chronic illness and disease state. Eur J Cancer Care. 2011;20(2):276-82.

19. Mota MS, Gomes GC, Petuco VM, Heck RM, Barros EJL, Gomes VLO. Facilitators of the transition process for the self-care of the person with stoma: subsidies for nursing. Rev Esc Enferm USP [Internet]. 2015 [cited 2015 Ago 03];49(1):82-8. Available from: http://www.scielo. br/pdf/reeusp/v49n1/0080-6234-reeusp-49-01-0082.pdf

20. Spadaccio C, Barros NF. Terapêuticas convencionais e não convencionais no tratamento do câncer: os sentidos das práticas religiosas. Interface Comun Saúde Educ [Internet]. 2009 [citado 2011 out. 23];13(30):45-52. Disponível em: http://www.scielo.br/pdf/icse/v13n30/ v13n30a05.pdf

21. Alencar DL, Marques APO, Leal MCC, Vieira JCM. Fatores que interferem na sexualidade de idosos: uma revisão integrative [Internet]. Ciênc Saúde Coletiva [Internet]. 2014 [citado 2016 jan. 04];19(8):3533-42. Disponível em: http://www.scielosp.org/pdf/csc/v19n8/14138123-csc-19-08-03533.pdf

22. Gama CAP, Campos RTO, Ferrer AL. Saúde mental e vulnerabilidade social: a direção do tratamento. Rev Latinoam Psicopatol Fundam [Internet]. 2014 [citado 2015 jun. 10];17(1):69-84. Disponível em: http://www.scielo.br/pdf/rlpf/v17n1/v17n1a06.pdf

23. Silva LF, Alves F. Compreender as racionalidades leigas sobre saúde e doença. Physis. 2011;21(4):1207-29.

24. Karlsson M, Friberg F, Wallengren C, Öhlén J. Meanings of existential uncertainty and certainty for people diagnosed with cancer and receiving palliative treatment: a life-world phenomenological study. BMC Palliat Care [Internet]. 2014 [cited 2015 Jun 20];13:28. Available from: http://www.ncbi.nlm.nih.gov/pmc/articles/PMC4059734/

25. Heyes SM, Harrington A, Bond JM, Belan I. The lived experiences of people with bladder cancer and their partners. Cancer Nurs Pract. 2014;13(9):25-30.

26. Barret LF. Solving the emotion paradox: categorization and the experience of emotion. Pers Soc Psychol Rev. 2006;10(1):20-46. 
27. Leal I, Engebretson J, Cohen L, Rodriguez A, Wangyal T, Lopez G, et al. Experiences of paradox: a qualitative analysis of living with cancer using a framework approach. Psychooncology. 2015;24(2):138-46.

28. Hugles N, Closs SJ, Clark D. Experiencing cancer in old age: a qualitative systematic review. Qual Health Res. 2009;19(8):1139-53.

Financial support: Fundação de Amparo à Pesquisa do Estado de São Paulo (FAPESP). Process no. 2012/018764 and Conselho Nacional de Desenvolvimento Científico e Tecnológico (CNPq). Case no. 303522/2010-0. 